\begin{tabular}{|c|l|}
\hline Title & $\begin{array}{l}\text { How do sink and source activities influence the reproduction and vegetative growth of spring ephemeral herbs under } \\
\text { different light conditions? }\end{array}$ \\
\hline Author(s) & Sunmonu, Ninuola; Kudo, Gaku \\
\hline Citation & $\begin{array}{l}\text { Journal of Plant Research, 127(4), 503-511 } \\
\text { https://doi.org/L0.1007/310265-014-0640-4 }\end{array}$ \\
\hline Issue Date & 201407 \\
\hline Doc URL & http://hdl.handle.net/2115/59454 \\
\hline Rights & The final publication is available at link.springer.com \\
\hline Type & article (author version) \\
\hline File Information & JPR2014Sunmonu\& Kudo.pdf \\
\hline
\end{tabular}

Instructions for use 
J Plant Res (2014) 127: 503-511

\title{
How do sink and source activities influence the reproduction and vegetative growth of spring ephemeral herbs under different light conditions?
}

\author{
Ninuola Sunmonu ${ }^{1}$ and Gaku Kudo ${ }^{1}$ \\ ${ }^{1}$ Faculty of Environmental Earth Science, Hokkaido University, Sapporo 060-0810, \\ Japan
}

\begin{abstract}
Spring ephemeral herbs inhabiting deciduous forests commonly complete reproduction and vegetative growth before canopy closure in early summer. Effects of shading by early canopy closure on reproductive output and vegetative growth, however, may vary depending on the seasonal allocation patterns of photosynthetic products between current reproduction and storage for future growth in each species. To clarify the effects of sink-source balance on seed production and bulb growth in a spring ephemeral herb, Gagea lutea, we performed a bract removal treatment (source reduction) and a floral-bud removal treatment (sink reduction) under canopy and open conditions. Leaf carbon fixations did not differ between the forest and open sites and among treatments. Bract carbon fixations were also similar between sites but tended to decrease when floral buds were removed. Seed production was higher under open condition but decreased by the bract-removal treatment under both light conditions. In contrast, bulb growth was independent of light conditions and the bract-removal treatment but increased greatly by the bud-removal treatment. Therefore, leaves and bracts acted as specialized source organs for vegetative and reproductive functions, respectively, but photosynthetic products by bracts were flexibly used for bulb growth when plants failed to set fruits. Extension of bright period was advantageous for seed production (i.e., source limited) but not for vegetative growth (i.e., sink limited) in this species.
\end{abstract}

Key words: canopy closure, carbon fixation, cost of reproduction, spring ephemerals, seed production, photosynthesis 


\section{Introduction}

Spring ephemeral plants are characterized by short life cycles in the temperate deciduous forests. They emerge quickly in early spring when temperature is still cool and die back to their underground parts after a rapid growth and reproduction in early summer. They are mostly clonal and perennial (Whigham 2004) with yearly renewal of the underground parts. After shoot emergence, spring ephemerals assimilate carbon under high irradiance prior to canopy closure in the forest (Lapointe 2001; Rothstein and Zak 2001). This assimilated carbon may be directed towards vegetative growth and reproduction simultaneously. According to the resource allocation theory (Harper 1977; Watson 1984), there is a trade-off relationship in carbon allocation between reproduction and growth when they depend on same C-pool that is known as the cost of reproduction (Obeso 2002). Therefore, physiological interaction between vegetative growth and reproduction are important in the study of plants life history and resource use strategy.

In perennial plants, current photosynthesis and/or stored carbohydrate provide the resources needed for reproduction (Chapin et al. 1990) but the extent of contribution by each source can vary among species and even within species temporally (Ida and Kudo 2008; Kudo and Ida 2010). Resource dynamics during the growing season has been documented in several herbaceous species (Lapointe 1998; Garcia and Ehrlen 2002; Horibata et al. 2007; Ida and Kudo 2008; Kudo and Ida 2010; Kleijn et al. 2005). Species with a brief photosynthetic period and/or low resource availability often depend on storage for reproduction (Wardlaw 1990). Spring ephemerals with short growth period may fall into this category (Kudo and Ida 2010). Timing of leaf senescence in spring ephemeral species corresponds with the forest leaf display period and occurs 50-60 days after shoot emergence. Thus, overall carbon gain during the growing season may be limited thereby increasing the trade-offs between vegetative growth and reproduction. In addition, if present resource demand by reproductive sink surpasses current gain by assimilative source, reproductive function may compete with vegetative function for limited resource use. However, if sink and source organ can operate independently, reproduction and vegetative growth may not compete for resource use. Therefore, detail investigation of source and sink activity is necessary to understand the extent of trade-offs between reproduction and vegetative functions.

Gagea lutea is a polycarpic perennial herbaceous species having a typical spring ephemeral 
lifecycle. Reproductive plants have one basal leaf and a pair of leaf-like bracts on the scape. Each reproductive shoot bears multiple flowers on a single scape. The underground part (bulb) is a storage organ, which is the only tissue existing over years. Therefore, this species has two sources (leaf and bract) versus two sinks (fruit and bulb) in terms of carbon assimilation during a growth period. In the previous study (Sunmonu et al. 2013), we reported the compensative ability of bracts when photosynthetic products by bracts were used for current seed production. On the other hand, photosynthetic products by leaves were used for bulb development and carbon translocation to reproductive function was negligible. This indicated the different source functions between leaf and bract. However, detail understanding of the interaction between sink (vegetative growth and reproduction) and source functions (photosynthesis by leaves and bracts) is yet to be ascertained. The present study, therefore, was conducted to test the extent of the trade-offs between reproduction and vegetative functions by monitoring relationships between these organs. A previous study in this species reported a high seed set success at the forest edge than under the forest canopy (Nishikawa 2009). This result gives a clue that low light condition under the canopy is likely detrimental to plants fitness but more extensive analysis is needed on this conclusion. Hence, we performed an experiment in open and under forest condition to clarify if any, the effect of decreasing light condition under the forest on the sink-source abilities.

We aimed to clarify the sink-source relationships between reproductive output (fruit production) and vegetative growth (bulb growth) of spring ephemerals under different light conditions. To regulate the sink-source balance of whole plants, we compared the performance of reproductive intact (control), bract removal (source reduction for reproduction), and floral-bud removal plants (removal of reproductive sink) under forest and open conditions. We addressed the following predictions; (i) Carbon fixation by bracts will be decreased by the floral-bud removal if photosynthetic activity of bracts is sink limited, while carbon fixation by leaves may be independent of the treatments because of the fixed carbon translocation to the bulb. (ii) Vegetative growth (bulb size increment) will increase as following sequence: floral-bud removal $>$ intact $>$ bract removal, responding to the flexible carbon translocation by bracts, and this trend will be more clear in the open habitat if bulb growth is source limited. (iii) Reproductive output (seed-set success) will be higher in the intact plants than in the bract-removal counterparts with more seeds in the open habitat if seed production is source limited. 


\section{Materials and methods}

\section{Study Species and Experimental design}

Gagea lutea Ker-Gaul. (Liliaceae) is one of the earliest blooming spring plants on the forest floor of deciduous forests in northern Japan. Reproductive shoots emerge immediately after snowmelt at the same time of leaf expansion in early April, flowering progresses sequentially within inflorescences from late April to mid-May, fruits mature about 2 weeks after anthesis, and aboveground parts die back soon after canopy closure in early June (Fig. 1). This study was conducted with potted plants of $G$. lutea from the secondary deciduous forest in the campus of Hokkaido University, Sapporo of northern Japan in 2011 (but the measurements of leaf photosynthesis was conducted in 2010 as described later). Major canopy trees in this fragmented forest include Ulmus davidiana var.japonica, Cercidiphyllum japonica, Betula platyphylla var. japonica and Populus maximowiczii and the forest floor is always covered with G. lutea together with other spring ephemerals in the spring.

Prior to the experiment, bulbs were dug from this forest floor on 12 November 2010 and taken to the laboratory for the size measurement. Width $(W)$ and length $(L)$ of individual bulbs were measured with a digital caliper and the volume was estimated as $4 \pi \times r^{2} \times L / 3$ based on the shape of the bulb. This was taken as the initial size for each plant. After the measurement, they were planted in pots $(7.5 \mathrm{~cm}$ diameter and $10 \mathrm{~cm}$ depth) one by one with numbered tags for identification. Then, the pots were taken back to the forest, put in holes in order for the plant to be at the same depth as they normally grow. The floor of the forest was covered with snow from midDecember to early April.

After snowmelt in the next spring (7 April 2011), pots with reproductive plants $(n=78)$ were selected soon after shoot emergency and divided into two sets of three treatments; intact control ( $n$ $=13)$, bract removal $(n=13)$, and floral-bud removal $(n=13)$. Floral buds or bracts were removed with a forceps as soon as they appeared. All flowers of control and bract removal plants were handpollinated to maximize the seed production. Pollen donors for a hand-pollination were selected from multiple reproductive plants $>5 \mathrm{~m}$ apart from the recipient plants. The floral-bud and bract removal treatments were compared with the control plants to detect the contribution of each organ 
to the renewal of the underground part, carbon fixation (by leaf and bract), and seed production (only bract removal and control). All plants were monitored under the forest but just before canopy closure, one set of plants was transferred to an open site (18 May 2011). This was done to reveal the effect of continuous (at open site) rather than decreasing light level experienced in the forest floor (at forest site) on plant performance. Plants were watered sometimes to prevent soil desiccation. Photosynthetically active radiation (PAR) at $2 \mathrm{~m}$ above the ground was automatically recorded at 1-min intervals using a combined data logger with a solar radiation sensor (HOBO weather station; Onset Co., MA, USA) during the growing period (Fig. 1).

Individual bulb size (final bulb size) was measured once again on 21 October 2011 and the responses of final bulb volume to treatments (control, bract removal, and floral-bud removal) and light level (forest and open sites) were analyzed after the one-year experiment.

\section{Photosynthetic carbon gain}

The measurements of leaf and bract photosynthesis were conducted using naturally grown plants in the forest to reduce the risk of accidental damage of potted plants. Carbon fixation by leaf and bract was evaluated based on the census of leaf or bract growth, seasonal transition of photosynthetic activity, and ambient solar radiation (for details, refer Sunmonu et al. 2013). Seasonal changes in leaf and bract sizes were recorded by measuring length $(L)$ and width $(W)$ of all plants at both sites with a digital calliper at 10-day intervals except on rainy days throughout the growth period. Basal leaf and bract area $(A)$ was estimated as $A=0.83 \times L \times W\left(R^{2}=0.968, n=5\right)$ and daily changes in leaf and bract areas were quantified throughout the season. Leaf life duration of each plant was monitored until leaf senescence at the end of the season.

With a portable LI-6400 photosynthesis system (Li-Cor, Lincoln, NB, USA), photosynthetic rates of leaves per unit area were measured in three individuals randomly selected in the natural population for intact and the bud-removed plants at each of four growth stages: floral-bud stage (mid-April), flowering stage (late April), early-fruiting stage (mid-May), and late-fruiting stage (late May) in 2010. Similar measurement was performed on bracts in 2011 but only in intact plants. Removal of floral buds was performed seven days before the photosynthetic measurement. The measurement was performed under 10 light conditions $(2000,1500,1000,800,500,300,100,50$, 10 , and $0 \mu \mathrm{mol} \mathrm{m} \mathrm{s}^{-1}$ ) of PAR. Leaf temperature was set at $15^{\circ} \mathrm{C}$ and the humidity of incoming air 
during the measurement was maintained at 1.1 vapor pressure deficit (VPD, $\mathrm{kPa}$ ) at an ambient $\mathrm{CO}_{2}$ concentration of $380 \mu \mathrm{mol} \mathrm{mol}{ }^{-1}$. The net photosynthetic rate as a function of photon irradiance was expressed using a non-rectangular hyperbola (Marshall and Biscoe 1980), which is a decelerating function composed of four photosynthetic parameters; light-saturated photosynthetic rate, initial slope, degree of curvature, and dark respiration rate. Data obtained for individual plants were fitted to this equation by non-linear least-squares estimates of the parameters. Mean values of individual parameters obtained in each period were used as representative of photosynthetic capacity. Because the width of basal leaves and bracts was smaller than the chamber size $(2 \times 3$ $\mathrm{cm})$, we corrected photosynthetic parameters by the replacement of chamber area by actual leaf area that was included in the chamber.

Net photosynthetic rates per hour were estimated from hourly mean values of light availability and photosynthetic parameters obtained at each growth stage (i.e., floral-bud, flowering, early fruiting, and late fruiting stages). Next, daily carbon fixation (mg C) was calculated from the daily average photosynthetic rate, that was the average value of hourly net photosynthetic rates in each day ( 24 hours), multiplied by leaf or bract size in each time, then total carbon fixation (mg C) throughout the growth period was estimated by summing up the daily carbon gain till the end of growing season (determined by leaf life duration). In this estimation, it is assumed that the daily transitions of leaf and bract sizes correspond to the proportional increase or decrease in sizes between days of measurements (Sunmonu et al. 2013). Total assimilated carbon throughout the season by leaves and bracts was compared among treatments (intact control, floral-bud removal, and bract removal plants) between sites (open and under canopy) at individual plant level to investigate how the effect of treatments on the carbon fixation capacity is related to change in light level. Two caveats are however associated with this estimation. First, data from intact plants were used to estimate the carbon gain by the bract-removal treatment, as photosynthetic measurement was not performed on this treatment. Second, photosynthetic parameters from the natural plants were used to calculate the carbon fixation in the transferred plants. Keeping these in mind, there is possibility of under estimation of carbon fixation in the bract-removal group and the transferred plants.

\section{Seed production}


To clarify the effect of treatment and light condition on the reproductive output, infructescences from the intact and bract-removal plants from both open and forest sites were harvested before the opening of capsules. The numbers of mature seeds, aborted seeds and unfertilized ovules were counted for individual fruits. Then, the effect of treatments and light level on seed-set success (seed/ovule ratio) was assessed.

\section{Statistical analysis}

We performed analysis of covariance (ANCOVA) to compare the maximum leaf and bract sizes among treatments at the two sites in which initial bulb size (2010) was included as a covariate after log-transformation. Shapiro-Wilk test and Bartlett test were used to confirm normality and homogeneity of variances of data respectively before conducting ANCOVA. Final bulb sizes (2011) were compared among treatments between sites using a generalized linear model (GLM) postulated gamma error distribution with log-link function in which treatment and site were set as explanatory variables and initial bulb size (2010) of individual plant was included as an offset term after log-transformation. Total leaf and bract carbon fixations were analyzed using GLM postulated gamma error distribution with log-link function in which treatment and site were set as explanatory variables, and initial bulb size was included as an offset term after log-transformation to eliminate any size effect because significant size effects were detected in leaf and bract size (see results). Same GLM model was performed also for the comparisons of leaf and bract longevities in which treatment and site were set as explanatory variables. Seed-set (seed/ovule ratio) were compared between intact and bract removal treatment by GLM postulated a binomial error distribution with logit-link function in which treatment and site were set as explanatory variables. All statistical analyses were done using an open source system, R version 3.0.1 ( $\mathrm{R}$ Development Core Team 2013) and best-fit models were selected for individual GLMs based on the Akaike's information criterion (AIC).

\section{Results}

\section{Leaf and bract longevities and carbon fixations}

The life-span of basal leaves was longer at the open site than at the forest site $(t=2.94, P=0.0044)$ 
but the difference was less than 2 days $(49.4 \pm 0.2$ and $51.2 \pm 0.8$ S.E. days in intact plants at the forest and open sites, respectively, $n=13$ ). Although floral-bud removed plants tended to have longer life-span $(t=2.49, P=0.015)$, the differences between intact and bud removal treatments were rather small (2.3 and 0.9 days differences at the forest and open sites, respectively). Maximum leaf size was $18.89 \pm 0.54 \mathrm{~cm}^{2}($ mean $\pm \mathrm{SE}, \mathrm{n}=78)$, and there was no difference between sites $\left(F_{1,72}=0.20, P=0.65\right)$ and among treatments $\left(F_{2,72}=1.47, P=0.24\right)$. Leaf size was strongly size dependent $\left(F_{1,72}=37.44, P<0.001\right)$.

The life-span of bracts was $46.8 \pm 0.8$ and $48.3 \pm 1.2$ days at the forest and open sites, respectively. In the GLM conducted for bract longevity, both site and treatment effects were not selected by AIC. Therefore, photosynthetic periods of bracts were independent of light level and the existence of fruits. Maximum bract size was smaller at the open site $\left(F_{1,47}=4.77, P=0.034\right)$, and significantly larger in control plants $\left(8.72 \pm 0.90 \mathrm{~cm}^{2}, \mathrm{n}=25\right)$ than in bud-removed plants $(5.74$ $\left.\pm 0.35 \mathrm{~cm}^{2}, \mathrm{n}=26 ; F_{1,47}=18.95, P<0.001\right)$. This result indicated that bract size decreased when reproductive sink was removed. Bract size was strongly size dependent $\left(F_{1,47}=42.45, P<0.001\right)$.

Photosynthetic parameters obtained in each season and treatment (control and floral-bud removal) are indicated in Appendix 1. Estimated total carbon fixation by a leaf did not differ between sites and among treatments as both site and treatment effects were not selected by AIC (Table 1, Fig. 2a). Estimated total carbon fixation by a bract was also similar between sites, but significantly smaller in the bud-removed plants (Table 1, Fig. 2b). Furthermore, a significant interaction between treatment and site was detected for the bract carbon fixation. This was because a decrease in bract carbon fixation by the floral-bud removal was apparent only at the forest site (Fig. 2b).

\section{Seed production}

Light level as well as the bract removal treatment clearly influenced the seed-set success (Fig. 3). Seed-set was enhanced under bright condition and the bract removal treatment significantly reduced the seed production (Table 2). Bract-removed plants decreased the seed set by $53 \%$ at the forest site and $43 \%$ at the open site. This result indicates the importance of bract photosynthesis for seed production. 


\section{Bulb growth}

Bulb size after one year was influenced only by treatment but not by site as site effect was not selected by AIC (Table 3). This result indicates that vegetative growth was independent of light levels and the bract removal treatment did not affect bulb size significantly. However, the floralbud removal treatment significantly increased the bulb size, indicating that the failure of seed production increases the vegetative growth (Fig. 4).

\section{Discussion}

\section{Is carbon fixation sink-limited?}

Total carbon fixation by bracts was decreased by the bud-removal treatment at the forest site. This result supports our prediction that the assimilative activity of bracts is sink-limited. Furthermore, final bract size was reduced by the bud-removal treatment at both sites, suggesting that bract growth might depend on the existence of reproductive sink (i.e., flowers). On the other hand, both leaf size and total carbon fixation were not influenced by the site and treatment as expected. This means that leaf carbon fixation simply depends on the sink intensity of bulb because most foliar photosynthetic products are transported to the bulb in this species (Sunmonu et al. 2013).

Extension of bright period did not increase the total carbon assimilation in this experiment. Although the longevities of leaves and bracts were extended at the open site to some extent, their responses were relatively conservative. Previous studies demonstrated that vegetative growth of spring ephemerals was terminated by the increase in soil temperature because warm temperature activated the metabolic process of aging (Badri et al. 2007; Yoshie 2008). These studies suggest that growing season length of spring ephemerals may be determined by temperature regime but not by light environment. The time of transfer, i.e., initiation of canopy closure coincided with the maximum leaf size period, and leaf size and photosynthetic activity tended to decrease after that due to the progress of partial leaf senescence (Sunmonu et al. 2013). Therefore, delay of canopy closure may not contribute the carbon fixation of $G$. lutea as shown by other spring ephemerals (Gutjahr and Lapointe 2008; Gandin et al. 2011). 
The bud-removed plants developed bigger bulbs compared to the control and bract-removed plants, indicating that photosynthetic products by bracts could be translocated to the bulb when fruits are absent. Furthermore, the absence of significant difference in bulb size between the control and bract-removed plants indicates that bract photosynthesis basically contributes to seed production and there is no interference effect between seed production and bulb growth in this species as predicted by our previous study (Sunmonu et al. 2013).

Final bulb size did not increase at the open site irrespective of the continuous bright condition during the growth period, indicating that bulb growth is not source-limited. This is probably because bulb growth had been largely completed by the initiation of canopy closure in the forest before the transfer, and additional foliar photosynthesis did not contribute to further bulb growth as known in other forest herbs (Lapointe 2001; Gutjahr and Lapointe 2008). Furthermore, warm soil temperature at the open site could have limited the growth of bulb. Photosynthesis and stomatal conductance of spring ephemeral plants grown under warm conditions tended to decrease rapidly in late season in comparison with plants grown under cool conditions (Gandin et al. 2011). Such rapid decrease in the supply of photosynthetic products might inhibit further growth of bulbs. Fixed leaf phenology in response to light environment under forest may reflect the growth schedule of the spring ephemerals. Such a conservative growth response even under light rich conditions may occur when plant growth is sink-limited (Paul and Foyer 2001; Woodward 2002).

Alternative respiratory pathways might be increased under enhanced light level and/or temperature. For example, activities of cyanide-insensitive respiratory pathway are increased in tulip (Kanneworff and van der Plas 1994) and iris bulbs (Marissen et al. 1991) in response to environmental changes. Furthermore, numerous other species have shown increased respiratory loss in the underground bulbs under elevated $\mathrm{CO}_{2}$, as a means to prevent starch buildup in the leaf (Lambers 1982; Azcón-Bieto et al. 1983; Gutjahr and Lapointe 2008; Kawano et al. 1978) and subsequent feed-back inhibition of photosynthesis (Paul and Foyer 2001; Rolland et al. 2002), which may trigger earlier leaf senescence and smaller final bulb size. Although the respiration of bulb was not measured in our study, it was obvious that bulb growth of G. lutea was independent of the extension of bright period.

Is seed production source-limited? 
The seed production increased significantly at the open site but decreased by the bract-removal treatment as predicted. This indicates that seed production of G. lutea is source-limited. In our previous study (Sunmonu et al. 2013), we estimated that photosynthetic products by bracts could fully support the fruit development. On the other hand, some seeds were produced even in the bract-removed plants in our experiment. As a possible cause, carbon assimilation stored in the bulbs might be used for fruit development as reported in other spring ephemerals (Kudo and Ida 2010). Bulbs of G. lutea are composed of previous tissue and newly developing tissue at flowering stage: flowering shoot is connected to the old tissue and basal leaf is connected to the new tissue (Sunmonu et al. 2013).

Enhanced seed production at the open site might not be due to the increased carbon assimilation by bracts because estimated carbon fixation did not differ between the forest and open sites. Self-assimilation ability of young fruits may be related to the higher seed production at the open site because green parts of reproductive structures occasionally have high assimilatory capacity comparable to leaves (reviewed in Aschan and Pfanz 2003). Our previous study revealed that green fruits of G. lutea maintained relatively high photosynthetic ability until late fruiting period (Sunmonu et al. 2013). Fruit photosynthesis could compensate the respiratory loss but it was insufficient for self growth in the forest due to increasing shading in late growing season. At the open site, however, a positive carbon gain might be possible under bright conditions, resulting in the acceleration of seed production.

In conclusion, G. lutea did not increase the vegetative growth under open condition but did increase the reproductive output because of heterogeneous sink-source relationships between vegetative growth and reproductive activity. Hence, reproductive individuals benefitted from increased light level by increasing the seed production and maintaining the bulb growth rather than increasing it. Nevertheless, having recorded an increase in reproductive output, one might wonder why $G$. lutea are commonly found under the forest. Available explanations could be that probability of establishment in open condition is being constrained by dispersal limitation, suitable regeneration condition and/or competitive ability. Ehrlén and Eriksson (2000) found that availability of seeds was limiting recruitment of forest herbs in unoccupied patches. Further research is, therefore, needed to clarify the factors limiting G. lutea's distribution towards the open 
habitat.

\section{Acknowledgments}

We thank the following people for their help with digging and measuring of bulbs and in the field survey: Yukihiro Amagai, Yuta Aoshima, Rie Miyata, Dewi Tika and Doddy Juli Irawan. This study was partly supported by a grant-in-aid from the Japan Society for the Promotion of Science [23405006].

\section{References}

Aschan G, Pfanz H (2003) Non-foliar photosynthesis-a strategy of additional carbon acquisition. Flora 198:81-97

Azcón-Bieto J, Lambers H, Day DA (1983) Effects of photosynthesis and carbohydrate status on respiratory rates and the involvement of the alternative pathway in leaf respiration. Plant Physiol 72:598-603

Badri MA, Minchin PE, Lapointe L (2007) Effects of temperature on the growth of spring ephemerals: Crocus vernus. Physiol Plant 130:67-76

Chapin FS, Schulze ED, Mooney HA (1990) The ecology and economics of storage in plants. Annual Review of Ecology and Systematics 21:423-447

Ehrlén J, Eriksson O (2000) Dispersal limitations and patch occupancy in forest herbs. Ecology $81: 1667-1674$

Gandin A, Gutjahr S, Dizengremel P, Lapointe L (2011) Source-sink imbalance increases with growth temperature in the spring geophyte Erythronium americanum. J Exp Bot 62:3467-3479

Garcia MB, Ehrlén J (2002) Reproductive effort and herbivory timing in a perennial herb: fitness components at individual and population levels. Am J Bot 89:1295-1302

Gutjahr S, Lapointe L (2008) Carbon dioxide enrichment does not reduce leaf longevity or alter accumulation of carbon reserves in the woodland spring ephemeral Erythronium americanum. Ann Bot 102:835-843

Harper JL (1977) Population biology of plants. London Academic Press

Horibata S, Hasegawa SF, Kudo G (2007) Cost of reproduction in a spring ephemeral species, 
Adonis ramose (Ranunculaceae): carbon budget for seed production. Ann Bot 100:565-571

Ida TY, Kudo G (2008) Timing of canopy closure influences carbon translocation and seed production of an understory herb, Trillium apetalon (Trilliaceae). Ann Bot 101:435-446

Kanneworff WA, van der Plas LHW (1994) Respiration of mitochondria isolated from tulip bulbs stored at 5 and $17^{\circ} \mathrm{C}$. Physiol Plant 91:665-670

Kawano S, Takasu H, Nagai Y (1978) The productive and reproductive biology of flowering plants. IV. Assimilation behavior of some temperate woodland plants. J Coll Lib Arts Toyama Univ $11: 33-60$

Kleijn D, Treier UA, Muller-Scharer H (2005) The importance of nitrogen and carbohydrate storage for plant growth of the alpine herb Veratrum album. New Phytol 166:565-575

Kudo G, Ida TY (2010) Carbon source for reproduction in a spring ephemeral herb, Corydalis ambigua (Papaveraceae). Funct Ecol 24:62-69

Lambers H (1982) Cyanide-resistant respiration: a non-phosphorylating electron transport pathway acting as an energy overflow. Physiol Plant 55:478-485

Lapointe L (1998) Fruit development in Trillium. Plant Physiol 117:183-188

Lapointe L (2001) How phenology influences physiology in deciduous forest spring ephemerals. Physiol Plant 113:151-157

Marissen N, Kanneworff WA, van der Plas LHW (1991) Effects of anaerobiosis on ethylene production, respiration and flowering in iris bulbs. Physiol Plant 82:465-473

Marshall B, Biscoe PV (1980) A model for $\mathrm{C}_{3}$ leaves describing the dependence of net photosynthesis on irradiance. J Exp Bot 31:29-39

Nishikawa Y (2009) Significance of intra-inflorescence variation on flowering time of a spring ephemeral, Gagea lutea (Liliaceae), under seasonal fluctuations of pollinator and light availabilities. Plant Ecol 202:337-347

Obeso JR (2002) The cost of reproduction in plants. New Phytol 155:321-348

Paul MJ, Foyer CH (2001) Sink regulation of photosynthesis. J Exp Bot 52:1383-1400

R Development Core Team (2011) R: A language and environment for statistical computing. R Foundation for Statistical Computing, Vienna, Austria. http://www.R-project.org/

Rolland P, Moore B, Sheen J (2002) Sugar sensing and signaling in plants. Plant Cell 14:S185S205 
Rothstein DE, Zak DR (2001) Photosynthetic adaptation and acclimation to exploit seasonal periods of direct irradiance in three temperate, deciduous-forest herbs. Funct Ecol 15:722-731

Sunmonu N, Ida TY, Kudo G (2013) Photosynthetic compensation by the reproductive structures in the spring ephemeral Gagea lutea. Plant Ecol 214:175-188

Wardlaw IF (1990) The control of carbon partitioning in plants. New Phytol 116:341-381

Watson MA (1984) Developmental constraints: effect on population growth and patterns of resource allocation in a clonal plant. Am Nat 123:411-426

Whigham DF (2004) Ecology of woodland herbs in temperate deciduous forests. Ann Rev Ecol Syst 35:583-621

Woodward FI (2002) Potential impacts of global elevated $\mathrm{CO}_{2}$ concentrations on plants. Curr Opin Plant Biol 5:207-211

Yoshie F (2008) Effects of growth temperature and winter duration on leaf phenology of a spring ephemeral (Gagea lutea) and a summergreen forb (Maianthemum dilatatum). J Plant Res $121: 483-492$ 
Table 1. Results of GLMs for total carbon fixation by basal leaves and bracts among treatments (intact, bract-removal, bud-removal) and sites (forest, open). Only variables selected by AIC are shown.

\begin{tabular}{lcccr}
\hline Variables & Coefficient & S.E. & $t$ value & $P$ value \\
\hline Basal leaf* & & & & \\
Intercept & 4.996 & 0.036 & 138.3 & $<0.0001$ \\
Bract & & & & \\
Intercept** & 4.549 & 0.088 & 51.33 & $<0.0001$ \\
Bud-removal & -0.461 & 0.125 & -3.68 & 0.0006 \\
Open site & -0.224 & 0.125 & -1.79 & 0.080 \\
Bud-rem $\times$ Open & 0.450 & 0.177 & 2.54 & 0.014 \\
\hline *For leaf carbon fixation, effects of treatment and site were not selected by \\
AIC \\
**Intercept (treatment=intact, site=forest)
\end{tabular}

Table 2. Result of GLM for seed-set ratio per plant among treatments (intact, bractremoval) and sites (forest, open). Only variables selected by AIC are shown.

\begin{tabular}{lccrc}
\hline Variables & Coefficient & S.E. & \multicolumn{1}{c}{$t$ value } & $P$ value \\
\hline Intercept* & 0.95 & 0.061 & 15.60 & $<0.0001$ \\
Bract-removal & -1.18 & 0.068 & -17.35 & $<0.0001$ \\
Open site & 0.240 & 0.068 & 3.57 & $<0.001$ \\
\hline *Intercept (treatment=intact, site=forest). Interaction between \\
treatment and site was not selected by AIC.
\end{tabular}

Table 3. Result of GLM for bulb size among treatments (intact, bract-removal, budremoval) and sites (forest, open). Only variables selected by AIC are shown.

\begin{tabular}{lrrrr}
\hline Variables & Coefficient & \multicolumn{1}{c}{ S.E. } & \multicolumn{1}{c}{$t$ value } & \multicolumn{1}{c}{$P$ value } \\
\hline Intercept* & 0.0002 & 0.069 & 0.003 & 0.99 \\
Bract-removal & 0.069 & 0.099 & 0.69 & 0.50 \\
Bud-removal & 0.290 & 0.098 & 2.95 & 0.0042 \\
\hline
\end{tabular}

*Intercept (treatment=intact). Site effect was not selected by AIC. 


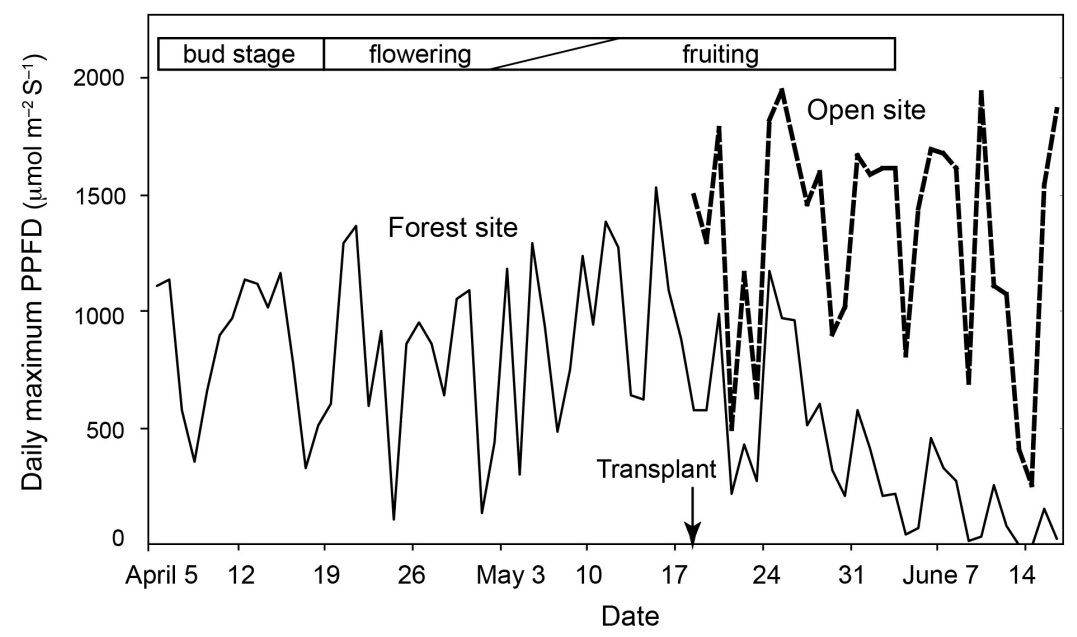

Fig. 1 Daily maximum photosynthetically active photon flux density (PPFD) at the forest (solid line) and open sites (broken line) during the growing season in 2011. Average periods of budding, flowering and fruiting are indicated. The transfer to open site was conducted on 18 May.
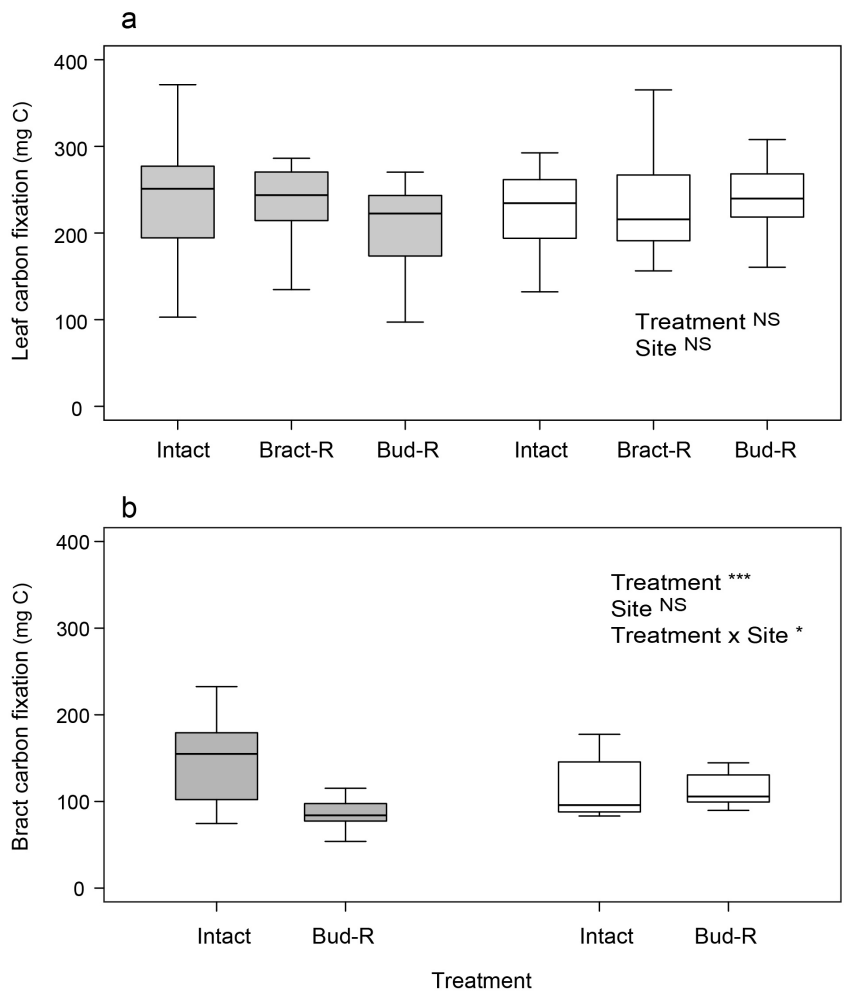

Fig. 2 Total carbon fixation by basal leaf (a) and bract (b) of intact, bract removal (only for a), and floral-bud removal plants throughout 2011 growth period at the forest (gray) and open sites (white). Carbon fixation values are adjusted for initial bulb size (Autumn 2010) to remove the size effect from the site and treatment effects. Box plots indicate 25,50 and 75 percentile and whiskers indicate 10 and 90 percentile of data distribution. Statistical results by GLM are indicated (see Table 1 for details). 


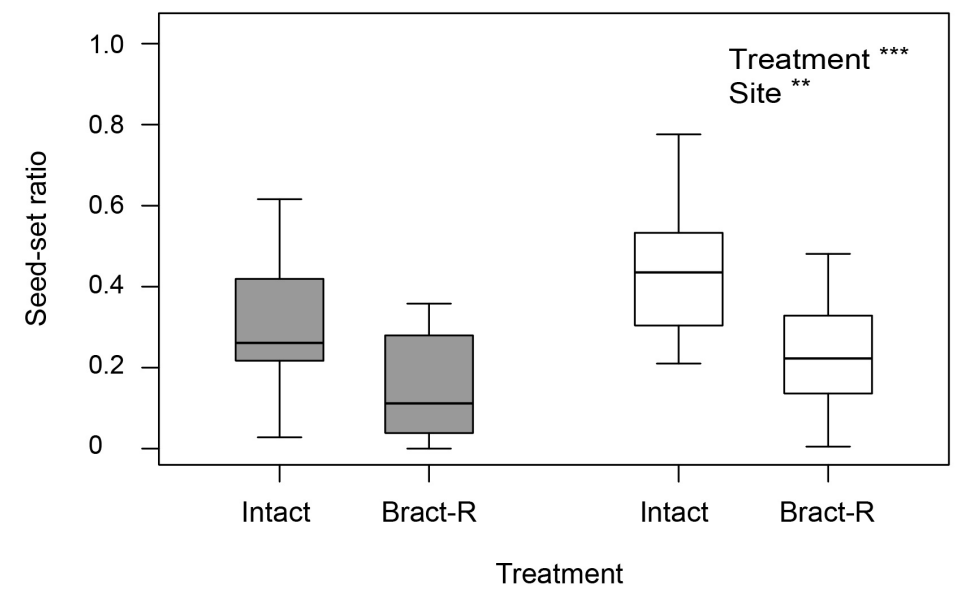

Fig. 3 Seed-set per plant at the forest (gray) and open sites (white) in the intact and bract removal treatments. Statistical results by GLM are indicated (see Table 2 for details).

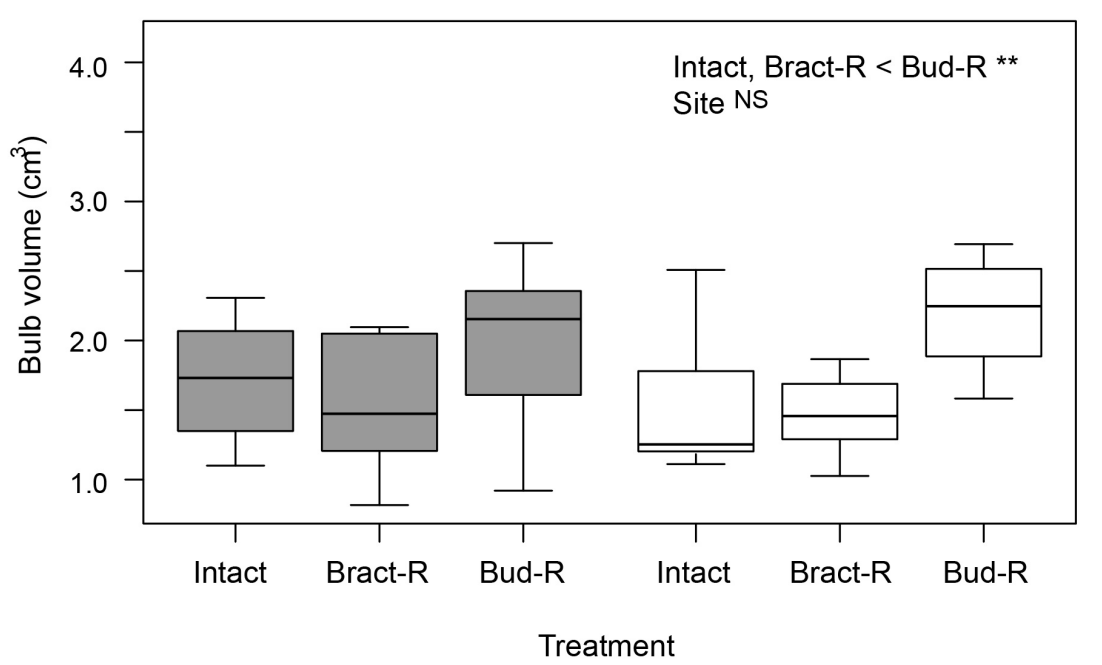

Fig. 4 Bulb volume after one-year experiment at the forest (gray) and open sites (white) in the intact, bract removal, and floral-bud removal treatments. Bulb volume values are adjusted for initial volume to remove the size effect from the site and treatment effects. Statistical results by GLM are indicated (see Table 3 for details). 